\title{
HYDROLYSED CASEIN FOR PARENTERAL ADMINISTRATION TO INFANTS
}

\author{
BY \\ YVONNE J. WILLIAMS, M.D., E. A. BISHOP, M.B., B.S., D.C.H., \\ and W. F. YOUNG, M.D., D.C.H.
}

(From the Children's Hospital and Department of Paediatrics and Child Health, University of Birmingham)

Since the year 1939, when preparations of protein digests became generally available in America, reports of investigations designed to test their value in the parenteral feeding of infants have appeared from time to time. 'Amigen,' an enzymic digest of hydrolysed casein, is one of these preparations. Shohl, Butler, Blackfan, and McLachlan (1939), using 'amigen' as the sole source of nitrogen in the diets of normal infants, found that it was as well utilized as the nitrogen supplied by an evaporated milk mixture so composed as to supply a similar quantity of food with the same percentage composition. Moreover, it was found that if the 'amigen' (again as the sole source of nitrogen) were given intravenously for periods of twenty-four hours, the subjects were still kept in a positive nitrogen balance comparable in magnitude with the balance obtained when the 'amigen' was given by mouth. Shohl (1943) also was able to show that infants suffering from gastro-enteritis were maintained in positive nitrogen balance when 'amigen' was given intravenously in quantities sufficient to provide the protein equivalent of at least $2 \cdot 2 \mathrm{~g}$. per $\mathrm{kg}$. per day, whereas similar infants who received only glucose solutions intravenously showed a negative nitrogen balance. Jonxis (1946) obtained good positive nitrogen balances by using solutions of 'capaine' (a digest of casein and lactalbumin prepared in Rotterdam) to supply a protein equivalent of about $2 \mathrm{~g}$. protein per $\mathrm{kg}$. per day. His subjects were suffering from only moderate degrees of food intolerance. Some reactions following the administration of 'amigen' have been reported, but later observers (Dodd and Rapoport, 1946) were able to give it for long periods to infants without the occurrence of reactions. They found, however, that thrombo-phlebitis at the site of the injection was often troublesome.

The present report* concerns a trial of a British enzymic digest of casein, 'casydrol', allocated by the Medical Research Council to the Children's

\footnotetext{
- Part I of a report prepared for the Medical Research Council's Committee on the Protein Requirements of Infants.
}

Hospital, Birmingham, for intravenous administration to infants. The biological efficiency of the material had been tested previously and it had been given to adults intravenously without the occurrence of reactions.

Fluid, Calorie, Protein, and Mineral Requirements

The aim of parenteral therapy is to supply adequate fluid and salts and at least maintenance requirements of calories and protein. Solutions of hydrolysed casein provide a mixture of polypeptides and amino acids likely to be well utilized, so that nitrogen equilibrium may be maintained if they are given in sufficient quantities. Casein is a better source of the sulphur-containing amino acids and of tryptophane than plasma (Williamson, 1944 ; Brand, Kassel and Saidel, 1944 ; Block and Bolling, 1944) and it is more easily obtained. The content of sodium and potassium in casein hydrolysate solutions is better balanced for the needs of the infant than it is in plasma. Sterile solutions of hydrolysed casein in sealed bottles can be stored indefinitely. Since the metabolic output is often raised under the stress of disease it may not be desirable or possible to cover the losses completely during the acute phase of an illness. If wasting is partially arrested, full repair can await a stage of convalescence at which oral feeding is well tolerated. The calorie value of the solutions at present available for intravenous infusions is low for two reasons, (a) stronger solutions of glucose and protein digests are irritative to the vein, and (b) emulsions of fat which would supply more calories have not yet been prepared on a large scale for intravenous use. It was decided to give infants requiring continuous intravenous infusions a total fluid intake of about $150 \mathrm{ml}$., containing 45 calories and at least $2 \cdot 2 \mathrm{~g}$. of protein equivalent per $\mathrm{kg}$. body weight per day (i.e. $2 \frac{1}{2}$ oz., 20 calories, and 1 g. of protein equivalent per $1 \mathrm{~b}$. body weight per day). These amounts are contained in 'casydrol' $(1 \cdot 7-2 \cdot 5$ per cent.) in 5 per cent. glucose solution given at a rate of about $6 \mathrm{ml}$. per $\mathrm{kg}$. (or $3 \mathrm{ml}$. per lb.) each hour. Blood and plasma which are sometimes given as part of the daily infusion, have a somewhat lower calorie value ( 20 instead of 28 per $100 \mathrm{ml}$.). 
The mineral requirements of the infant are inet by a maintenance infusion of 'casydrol ' and glucose as described above unless gross extrarenal losses are being sustained during the course of treatment, for example, in severe gastro-enteritis. If treatment is very prolonged, supplements of calcium may be required (Rapoport, Dodd, Clark, and Syllm, 1947). Table 1 shows the amounts of sodium, potassium, and cakcium in 'casydrol' glucose, 'amigen' glucose, and plasma glucose solutions compared with those in human milk and in cow's milk. The

TAVE 1

COMPOSITION OF SOLUTIONS OF CASEIN HYDROLYSATE AND PLASMA COMPARED WITH HUMAN AND COW'S MILK

\begin{tabular}{|c|c|c|c|c|c|}
\hline Fluid & 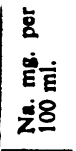 & 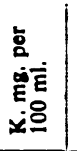 & 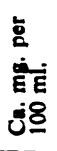 & 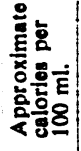 & 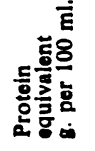 \\
\hline $\begin{array}{l}\text { - Casydrol '2t per cent. in } \\
5 \text { per cent gurcose }\end{array}$ & $\begin{array}{l}117 \\
\text { or less } \\
\end{array}$ & $42 \pm$ & 1 & 28 & $\underset{2 \cdot 25}{\text { About }}$ \\
\hline $\begin{array}{l}\text { - Amigen' 21 per cent. in } \\
5, \text { per cent. glucose }\end{array}$ & 52 & $7 \cdot 5$ & 10 & 29 & 1.9 \\
\hline $\begin{array}{l}\text { Thame } 50 \text { per cent. in } \\
5 \text { per cent. elucose }\end{array}$ & 167 & 10 & 5 & 30 & $2 \cdot 5$ \\
\hline Finman milk & 11 & 48 & 34 & 70 & $1 \cdot 0-1 \cdot 5$ \\
\hline Cow's milk & 61 & 154 & 122 & 70 & $3 \cdot 0-3 \cdot 5$ \\
\hline
\end{tabular}

calorie values and the percentage protein equivalent are also shown. Since the amount of sodium contained in a continuous daily infusion of 'casydrol may be equivalent to as much as $1 \cdot 5-2 \cdot 0 \mathrm{~g}$. sodium chloride for a $10 \mathrm{lb}$. infant per day, and more than this is given if the infusion is being supplemented by blood or plasma, it is necessary to watch for signs of salt retention, such as oedema, and to regulate the therapy accordingly. Halfstrength plasma contains more sodium and less potassium, while $2 \frac{1}{2}$ per cent. ' amigen' contains less of both these electrolytes than $2 \frac{1}{2}$ per cent. 'casydrol.' An infusion fluid can be used more freely if the salt content is low, and therefore a preparation of 'casydrol' with a sodium content similar to that of 'amigen' would be preferable for administration to infants.

\section{Method of Administration}

At the beginning of our investigation 'casydrol ' was available only as a 5 per cent. solution in 5 per cent. glucose. In order to give the estimated maintenance requirements of protein $(2 \cdot 2 \mathrm{~g}$. per $\mathrm{kg}$. per day) to infants, one-third of the solution together with two-thirds of 5 or 10 per cent. glucose were used, thus diluting the strength of the 'casydrol' to 1.7 per cent. This method was chosen instead of alternating 'casydrol' ghucose with simple glucose solutions because it was thought (1) that the weaker dilution might be less irritating to the veins, and (2) that the utilization of a minimal daily nitrogen intake might be higher if it were given evenly throughout the twenty-four hours rather than in larger amounts for shorter periods.

The use of the weak 'casydrol' solution proved to be satisfactory in so far as no difference was observed between the 'life' of veins which received it and those which received glucose solutions alone. This finding is contrary to the experience of observers using 5 per cent. ' casydrol' solutions for infants. The 1.7 per cent. solution given at the rate of $150 \mathrm{ml}$. per $\mathrm{kg}$. per day supplies only a minimal protein intake and it was found that the volume of the infusion sometimes fell short of this amount owing to technical difficulties. Accordingly, it was decided to increase the strength to 2.5 per cent. The manufacturers supplied a $2 \frac{1}{2}$ per cent. ' casydrol' in 5 per cent. glucose solution which could be given directly, thus avoiding the risks from contamination when mixing the solutions. The 'maintenance' infusion containing 'casydrol' was never given to patients until any dehydration present had been relieved by glucose and salt solutions and a free flow of urine had been established.

Apparatus. The apparatus used for the infusion was modified as the investigation proceeded. At first the reservoir consisted of an open flask $(100-250 \mathrm{ml}$.) covered with gauze and the only precautions against contamination were (1) careful aseptic technique at times when the flask was being refilled, and (2) a complete change of apparatus every twenty-four hours. Warnings of the grave risks accompanying the administration of amino acid solutions by the open method have been given by Dodd and Rapoport (1946). In 1947 Walton designed a closed apparatus suitable for administering continuous infusions to infants and this technique has been adopted. The apparatus has been used with satisfactory results and occasional bacteriological tests of the infusion fluid from various parts of the system have always shown it to be sterile. The open method was used in forty-six, and the closed in fifteen cases.

\section{Vitamin Sapplements}

Patients receiving intravenous infusions need vitamin supplements, and these should be given in optimum doses in order that any tendency to a deficiency may be overcome. Our patients have received vitamins intramuscularly and a single injection daily has usually been given. The following may be safely mixed in a syringe immediately before administration:
'Beminal' 1 ml.
Ascorbic acid, 50-100 mg.
'Synkavit' $0 \cdot 5-1 \mathrm{ml}$.
Aneurin, $10 \mathrm{mg}$.
Riboflavin, $0.5 \mathrm{mg}$.
Nicotinic acidamide, $25 \mathrm{mg}$.
Pyridoxin, 0.5 mg.
Pantothenic acid, 0.5 me.
Tetra-sodium salt of menaph- thone diphosphate, 5-10 mg.

Patients suffering from severe infection and those receiving prolonged treatment have also been given 
Vitamin A, as 'davitamon A. forte' $0.5 \mathrm{ml}$., on alternate days, supplying 30,000 units per dose. Crude liver extract combined with Vitamin B preparations such as 'plexan' and 'heparglandol ' ( $2 \mathrm{ml}$. alternate days) have sometimes been used instead of the 'beminal,' particularly for patients with clinical enlargement of the liver.

\section{Antibiotics}

All patients receiving parenteral fluids should be given penicillin with or without a sulphonamide preparation as a prophylactic measure against infection, and in many cases antibiotics are specifically indicated as part of the treatment of the primary disease. Penicillin has been given to our patients intramuscularly $(10,000$ units per $\mathrm{kg}$. per day in divided doses at three- to six-hourly intervals). When oral feeding has been resumed penicillin has sometimes been given by mouth $(240,000-360,000$ units per day to the smaller babies according to their age). Sulphonamides have been administered intravenously and subcutaneously. Since these drugs must not be mixed with infusions of ' casydrol ' or plasma, it has become customary to give them subcutaneously. A 5 per cent. solution of sulphadiazine in lactate-ringer (or saline) solution (Forbes, Donnell, and Herweg, 1947) is well tolerated, and the dose is $0 \cdot 1-0 \cdot 15 \mathrm{~g}$. per $\mathrm{kg}$. body weight per twenty-four hours in divided doses at twelve-hourly intervals. This method of administration has been found to maintain high concentrations in the blood. The levels have been checked frequently and the dose modified accordingly. When oral feeding has been resumed sulphadiazine has been continued by mouth, the dose being raised to $0.3 \mathrm{~g}$. per $\mathrm{kg}$. body weight per twenty-four hours in divided doses threehourly or four-hourly according to the intervals used for feeding.

\section{Subjects for the Investigation}

Sixty-one patients were selected for the trial of 'casydrol' all suffering from conditions which had necessitated the withdrawal of oral feeding for periods of several days. At the beginning of the investigation 'casydrol' was given to patients who were already receiving intravenous infusions and were in the terminal stages of an illness; this was not expected to affect the course of their disease (group A, three patients). Other patients were only given occasional infusions of 'casydrol', so that results from them can be used to judge tolerance to the injection but not other effects (group B, twenty patients). The remaining thirty-eight patients who received 'casydrol' intravenously were given amounts which reached the estimated requirements for maintenance infusions. In some, however, the infusions were continued for short periods only, either because of rapid improvement allowing a change over to oral feeding, or because they died (group C, twelve patients). Group D (twenty-six patients) were treated systematically for several days and their progress has been examined in detail, the salient points being shown in table 3 . The infants have been arranged under the following clinical headings:

1. Those with congenital obstructions of the alimentary tract.

2. Those suffering from peritonitis and paralytic ileus.

3. Those suffering from severe gastro-enteritis.

Classifying the sixty-one subjects of this investigation according to these categories, table 2 shows the type of treatment given (Groups A, B, C, D) and the rates of recovery or death.

\section{Resilts}

There have been no general reactions (of the type to indicate pyrogenic activity in the fluid being administered) in the sixty-one infants to whom continuous intravenous infusions of 'casydrol' have been given. A more rapid injection by syringe was given on two occasions to one small infant (C.K., No. 5) because her veins were not suitable for continuous intravenous infusion. The child became temporarily collapsed as the result of each injection, but there were no permanent effects. After this experience rapid administration of 'casydrol' was no longer practised. Warnings against this method are to be found in the literature (Kozoll, Hoffmann, and Meyer, 1945). There has been no apparent increase in the incidence of local reactions at the site of injections since maintenance infusions of 'casydrol' solution have been used in place of glucose solutions alone or glucose solutions and plasma. The veins of an infant vary in their tolerance to continuous intravenous infusions, but they can be used for at least forty-eight hours and

TARE 2

CLASSIFICATION OF SIXTY-ONE INFANTS RECEIVING • CASYDROL' SOLUTION INTRAVENOUSLY

\begin{tabular}{|c|c|c|c|c|c|c|c|c|}
\hline \multirow[b]{2}{*}{ Disease } & \multicolumn{4}{|c|}{ Unsystematic Administration } & \multicolumn{4}{|c|}{ Systematic Administration } \\
\hline & \multicolumn{2}{|c|}{$\begin{array}{l}\text { Group A. } \\
\text { Moribund }\end{array}$} & \multicolumn{2}{|c|}{$\begin{array}{l}\text { Group B. } \\
\text { Interrupted Treatment }\end{array}$} & \multicolumn{2}{|c|}{$\begin{array}{l}\text { Group C. } \\
\text { Short Treatment }\end{array}$} & \multicolumn{2}{|c|}{$\begin{array}{l}\text { Group D. } \\
\text { Long Treatment }\end{array}$} \\
\hline $\begin{array}{l}\text { 1. Conenital obstructions } \\
\text { Pyloric stenosis }\end{array}$ & Recovered & Died & $\begin{array}{c}\text { Recovered } \\
0\end{array}$ & Died & $\begin{array}{c}\text { Recovered } \\
0 \\
1\end{array}$ & $\begin{array}{c}\text { Died } \\
1 \\
1\end{array}$ & $\underset{0}{\text { Recovered }}$ & ${ }_{2}$ \\
\hline \begin{tabular}{llll|} 
2. Peritonitis with paralytic \\
ileus & $\ldots$ & $\ldots$ & $\ldots$
\end{tabular} & $\mathbf{0}$ & 1 & 2 & 4 & 1 & $\mathbf{0}$ & 5 & 2 \\
\hline 3. Severe gastro-enteritis ... & $\mathbf{0}$ & 1 & 3 & 10 & 7 & 1 & 14 & 3 \\
\hline Total & 0 & 3 & 5 & 15 & 9 & 3 & 19 & 7 \\
\hline
\end{tabular}




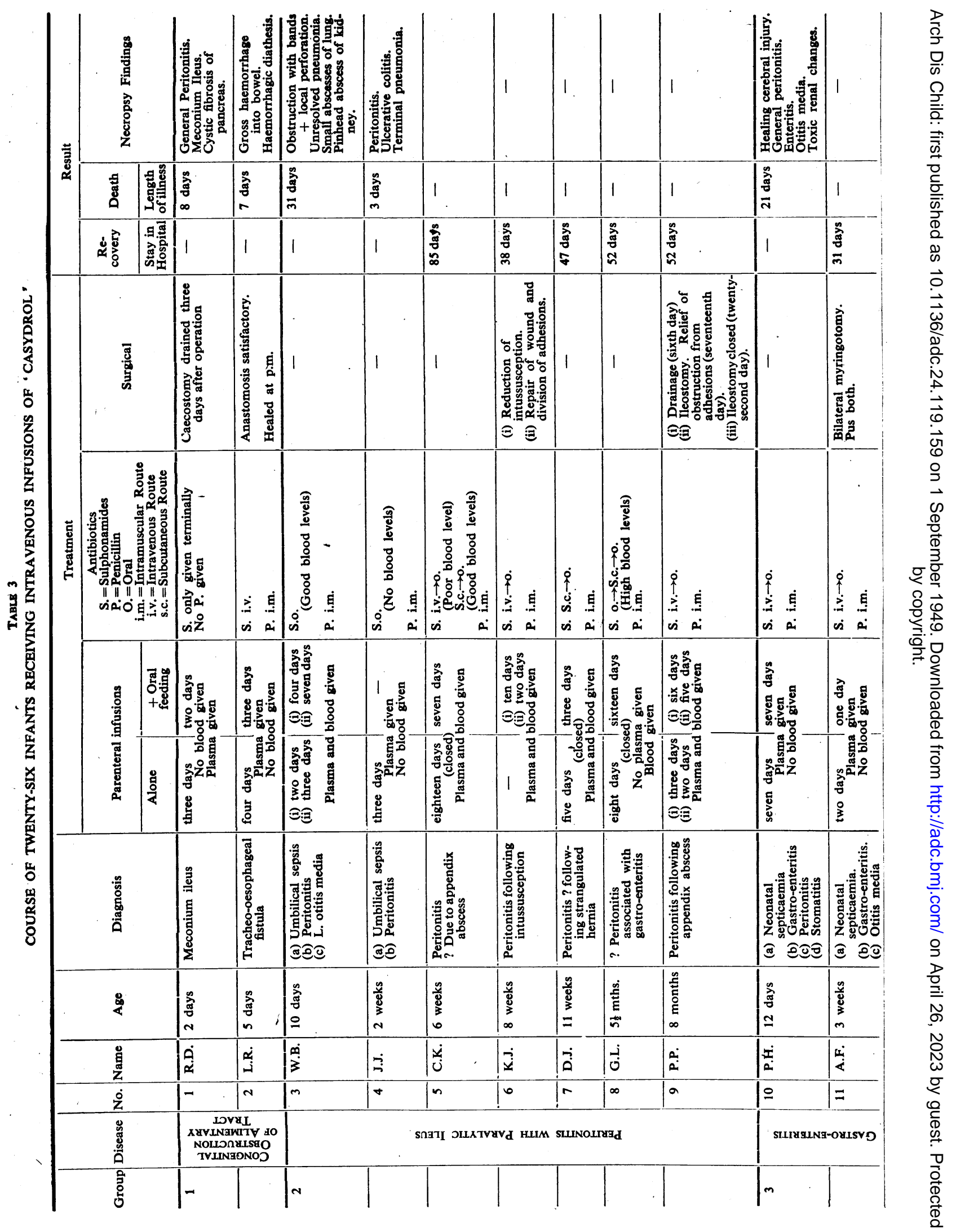




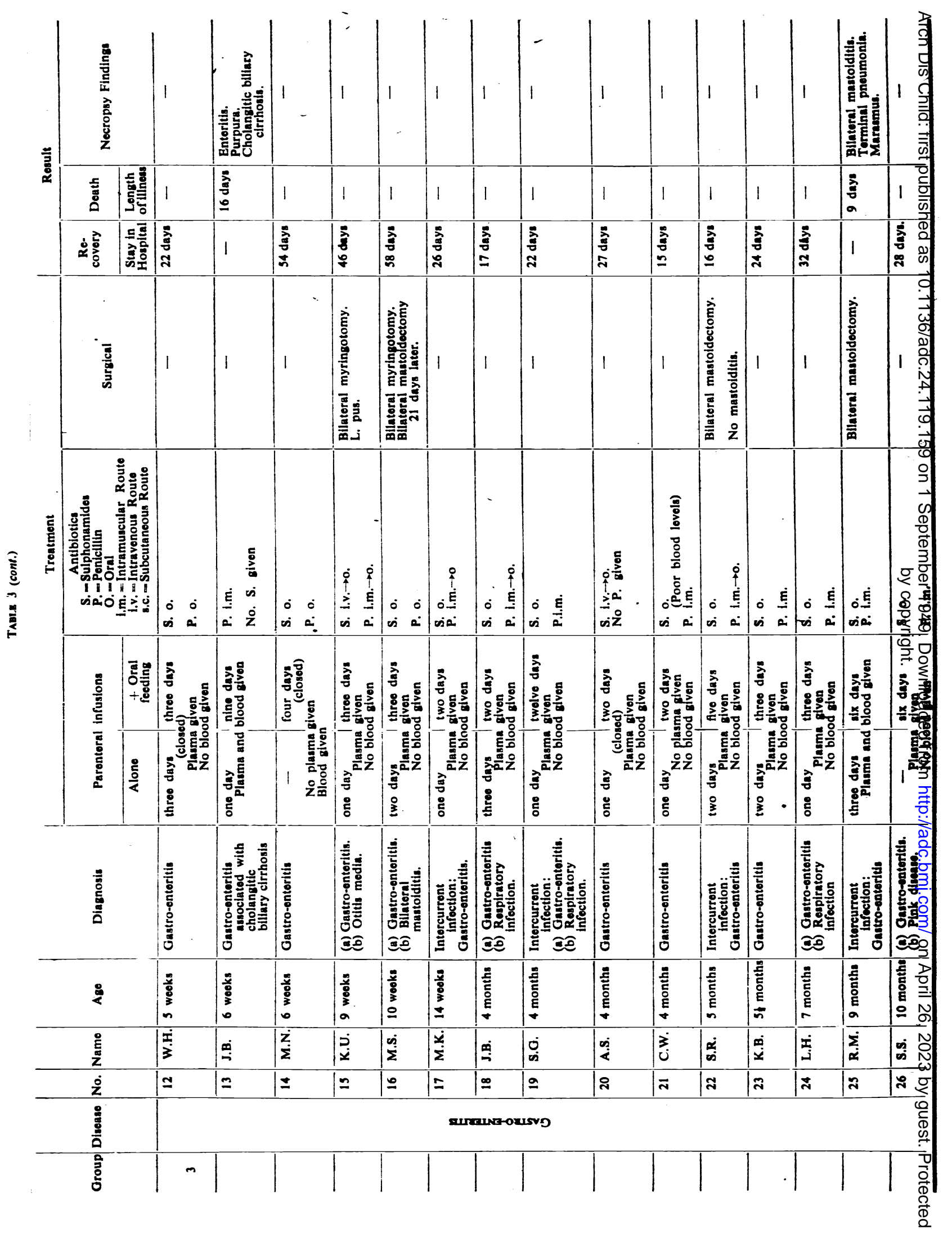


have often been used for three or four days continuously.

Only one infant who had been given infusions of ' casydrol' showed evidence at necropsy that the cause of death was likely to have been associated with the infusion. Septic thrombo-phlebitis (a complication of intravenous therapy of any kind) had occurred and multiple abscesses were present in the lungs. The child was admitted suffering from gastro-enteritis and death occurred thirteen days later from staphylococcal septicaemia.

Pyaemia was found in three other cases, but sites of infection were present which might have led to septic embolism. The open method was still being used at the time that these four patients were being treated.

Progress of twenty-six cases (Group D). Table 3 shows the cases divided into the three clinical groups which were used in Table 2 . It will be seen that there were two cases of congenital obstruction of the alimentary tract, seven cases of peritonitis with paralytic ileus, and seventeen cases of severe gastroenteritis. Supportive measures with parenteral feeding are a corollary to surgical treatment in treating congenital obstructions of the alimentary tract, while the treatment of infection is of primary importance in peritonitis and gastro-enteritis. These three aspects of treatment have therefore been stressed in reviewing the progress of our patients. Table 3 shows that in one case (No. 5) parenteral infusions were the sole source of nutrition for as long as eighteen days and that they were used to supplement the oral intake for a further period of seven days. Such prolonged treatment is not usually required, and the duration of parenteral therapy in the other cases varied from one to eight days for complete, and from one to sixteen days for supplementary intravenous infusions. There were seven deaths, a mortality rate of 27 per cent. Two of the deaths occurred in patients who had congenital obstruction of the alimentary tract, and both babies had made satisfactory progress during the early phase of post-operative treatment. Necropsy findings show that one died from general peritonitis and the other from an acute haemorrhagic diathesis. It is possible that these conditions might have been prevented by more systematic treatment; in the one, by the administration of antibiotics in the earty days after operation, and in the other by small blood transfusions and continuation of Vitamin $K$ supplements for a longer period. Surgical treatment had been successful in both cases. Two deaths occurred in the infants suffering from peritonitis and three in those suffering from severe gastro-enteritis. The clinical course and the necropsy findings in these patients suggest that death from the primary diseases could not have been prevented by treatment. Case 3, who had umbilical sepsis, was one of those showing a terminal miliary spread of infection which might have been introduced by the infusion fluid, or which might equally well have been due to the primary infection.
Trentment and progress of seven cases. Figs. 1 to 7 illustrate the treatment of cases $5,7,9,10,12,20$, and 22 . As is shown in table 3 cases 5,7 , and 9 were infants suffering from peritonitis and paralytic ileus while the remainder were babies with gastroenteritis.

The construction of figures, together with systematic records of the vitamin supplements and antibiotics which are being given, are valuable aids to efficient treatment. It has been our practice to keep daily records of the intake on a table which is a modification of the one described by Dodd and Rapoport (1946).

CASE No. 5. C.K. This infant aged six weeks and weighing $6 \mathrm{lb} .10 \mathrm{oz}$. was admitted with a history of vomiting for one week, and abdominal distension and constipation for five days (fig. 1). On examination the abdomen was found to be grossly distended, and peritonitis of unknown etiology was diagnosed. The patient was slightly dehydrated and was lethargic. She had a raised pulse rate and became pyrexial. Surgical interference was not advised.

Penicillin was given by the intramuscular, and sulphadiazine by the intravenous routes. Infusions of plasma and glucose were given to relieve dehydration, and later $2 \frac{1}{2}$ per cent. 'casydrol 'solution with 5 per cent. glucose plus small blood and plasma transfusions were substituted according to the schedule of her requirements. Oral feeding was withheld, but sulphadiazine was given by mouth on the fourth day. The infant's general condition improved in response to treatment, but signs of peritonitis were persistent. The baby was hungry and on the eleventh day oral feeding was attempted, but it had to be discontinued on the thirteenth day owing to increasing abdominal distension. The sulphonamide level in the blood had only been of the order 3 to $7 \mathrm{mg}$. per $100 \mathrm{ml}$., and in order to raise it subcutaneous administration of sulphadiazine was begun on the fourteenth day. The level on the sixteenth day was found to be $15.5 \mathrm{mg}$. per $100 \mathrm{ml}$. On the twenty-first day bowel movements were resumed and the abdominal distension began to subside. Subsequently, oral fluids were well tolerated and milk feeds were introduced slowly. Food was badly tolerated and the baby became extremely marasmic, weighing only $5 \mathrm{lb}$. $11 \mathrm{oz}$. on the thirty-fourth day. Later she tolerated food well, and was fed according to a scheme for marasmic infants which will be described in a subsequent paper (Young, Bishop, Hickmans, and Williams, 1949). She was discharged on the eighty-fifth day weighing $7 \mathrm{lb} .7 \mathrm{oz}$. and continued to make good progress at home. When seen again at the age of nine months she seemed to be a normal healthy baby and weighed $19 \mathrm{lb}$.

CASE No. 7. D.J. This infant aged 11 weeks and weighing about $10 \mathrm{lb}$. was admitted with a history of vomiting of increasing severity and of constipation for two days (fig. 2): A lump in the groin had been noted for one day. On examination there were signs of acute abdominal obstruction 

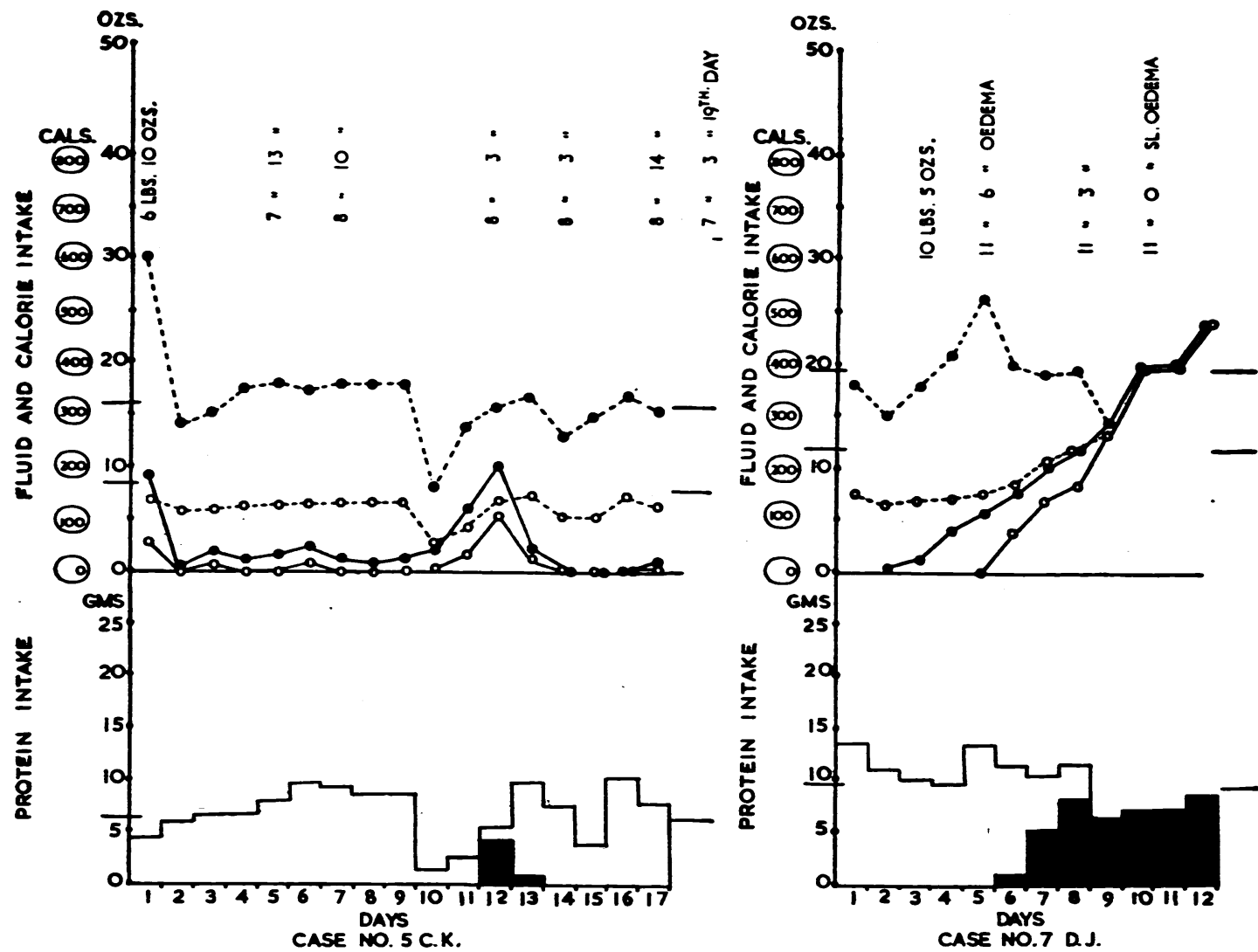

FIG. 1.

(See footnote for key to charts)

FrG. 2.

possibly due to a strangulated hernia which had reduced itself. The vomits consisted of thick mucus with a faecal odour. The patient was pyrexial and had a raised pulse rate. There were signs of shock at the time of admission. Surgical treatment was not advised.

Penicillin was given by the intramuscular, and sulphadiazine by the subcutaneous, routes. The stomach contents were aspirated by a Ryle's tube. Infusions of plasma and glucose were given until dehydration had been relieved on the second day, and subsequently those of $2 \frac{1}{2}$ per cent. 'casydrol' in 5 per cent. glucose with the usual additions of blood transfusions and of vitamin supplements were substituted. The child's condition remained critical for two days. On the third day there were signs that the obstruction was relieved. A high sulphonamide level of $30 \mathrm{mg}$. per $100 \mathrm{ml}$. in the blood was

\footnotetext{
- Daily fluid intake in oz. (oral).

......... Daily fluid intake in oz (oral + intravenous).

- -......... Daily calorie intake (orad

$0 \ldots \ldots \ldots . . .0$ Daily calorie intake (oral +intravenous).

Back block

Daily protein intake in $\mathrm{g}$ (oral).

Daily protein intake in 8 (intravenous).

The horizontal lines on the vertical scale of the figures at three levels represent from above downwards the estimated maintenance requirements of fluid (2t-2t oz per lb.). calories (20 per lb.), and protein $(1 \mathrm{~g}$ per lb.).
}

reached on the second and fourth days. It fell to $16 \mathrm{mg}$. per $100 \mathrm{ml}$. on the fifth day. On the fourth day the general condition had greatly improved, but the infant had become oedematous. Oral fiuids were gradually substituted for the intravenous infusion and were well tolerated. Intravenous infusions were therefore discontinued on the eighth day, although only a minimal intake was being provided by the diet. Later the quantity of food was increased, and the patient, now weighing $11 \mathrm{lb} .4 \mathrm{oz}$., was discharged on the forty-seventh day.

CASE No. 9. P.P. This baby aged five and a half months, and weighing about $14 \mathrm{lb}$., was admitted with a history of copious vomiting and of constipation for five days (fig. 3). On examination the abdomen was found to be distended and 'doughy.' The patient was pyrexial and had a raised pulse rate. She was moderately dehydrated.

Antibiotics were prescribed. Intravenous infusions for the relief of dehydration and for maintenance were given as in Cases 5 and 7. The signs of peritonitis persisted and laparotomy was performed on the sixth day when a large purulent effusion was found. The appendix was thought to be the origin of the suppuration but was not located. The 


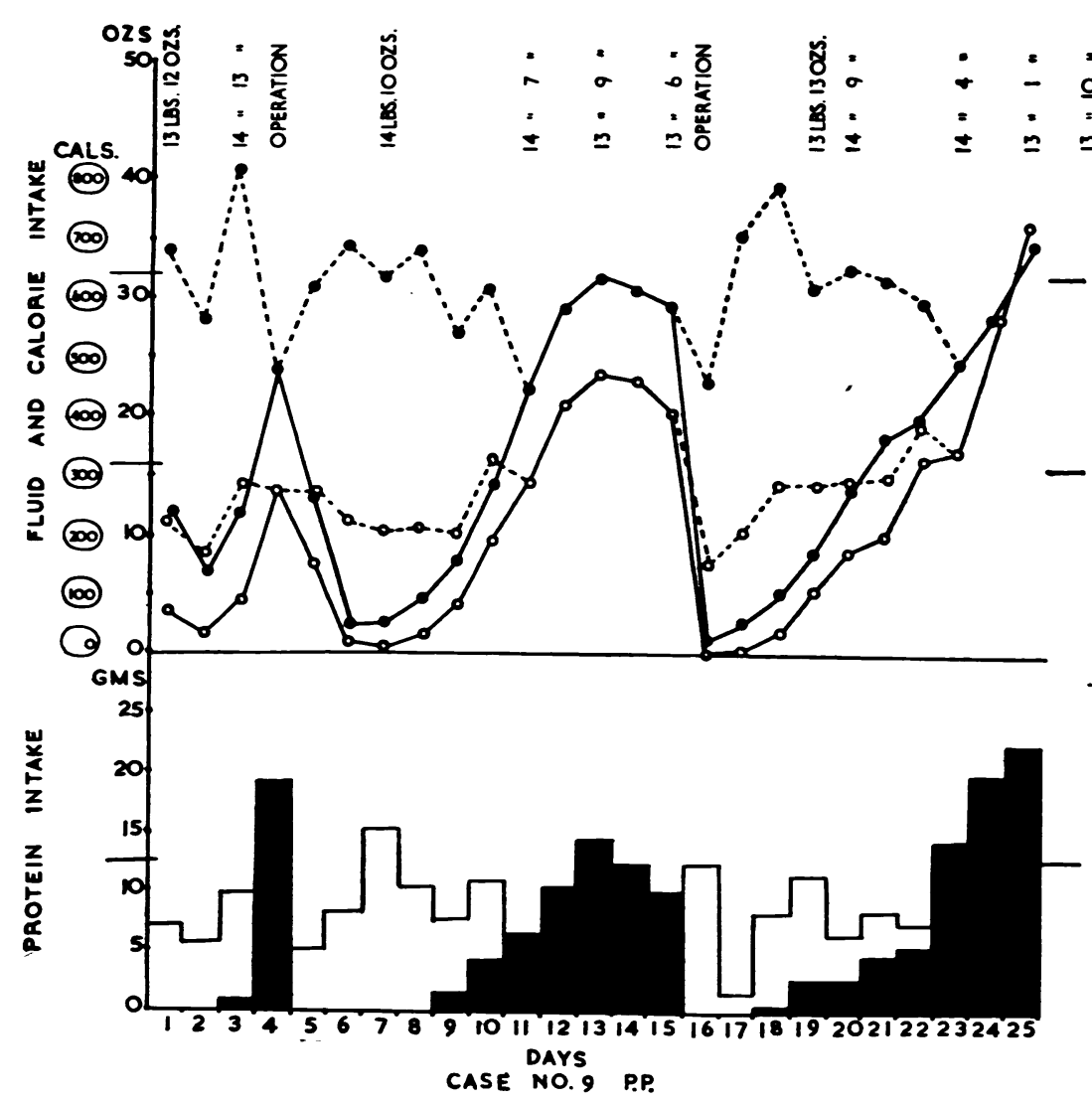

FIG. 3.

CASE No. 10. P.H. This infant, twelve days old and weighing $7 \mathrm{lb}$., was admitted with a history of feeding difficulties from birth. Stools had been of the starvation type (fig. 4). On examination the patient was found to be toxic and dehydrated, but the only abnormal signs were slight umbilical sepsis and a haematoma over the left occipital bone. General neonatal infection was suspected.

Antibiotics were prescribed. Infusions were given to relieve dehydration and oral feeding was attempted, but was badly tolerated. Accordingly, a maintenance infusion with the usual additions of plasma was given. There was never any improvement in response to treatment. Generalized oedema developed following a plasma transfusion and a total salt intake of $2 \mathrm{~g}$. On the fifth day. Further attempts were made to feed the child by mouth but without success. His condition deteriorated and he

abdomen was drained and discharged freely during the post-operative period. Culture of the pus yielded Bact.coli and a streptococcus. Paralytic ileus persisted after operation and it was treated by gastric suction, chemotherapy, and continuation of intravenous infusions. As may be seen from fig. 3, however, 'maintenance' requirements of calories and protein were not always reached. On the tenth day (i.e. four days after operation) bowel movements were resumed and oral fluids were allowed, and by the thirteenth day, oral feeding was sufficient to provide an adequate fluid intake. On the seventeenth day, there was a sudden recurrence of vomiting and abdominal distension. A second laparotomy was performed and the obstruction was found to be due to adhesions. These were divided and an ileostomy was performed, which began to function after two days and was closed after five days. Oral feeds were introduced, but it was not until the twenty-third day, and six days after the second operation, that intravenous infusions could be discontinued. Progress thereafter was satisfactory and the patient was discharged in good health on the fifty-second day. died on the sixteenth day. Post-mortem examination revealed a cerebral birth injury and multiple infections (see table 3).

CASE No. 12. W. H. This infant aged five weeks and weighing $7 \mathrm{lb}$. $8 \mathrm{oz}$., was admitted with a history of vomiting for five days and diarrhoea for two days (fig. 5). On examination the patient was found to be grossly dehydrated with signs of circulatory failure. Primary gastro-enteritis was diagnosed.

Antibiotics were prescribed. Infusions were given to relieve dehydration and after forty-eight hours the child's general condition was greatly improved. The diarrhoea had persisted, however, and it was decided to withhold food and to give the maintenance infusion containing 'casydrol.' This was continued between the second and fifth days. By this time the diarrhoea had subsided and oral feeding was well tolerated. The patient, weighing $8 \mathrm{lb} .6 \mathrm{oz}$., was discharged well on the twenty-second day.

CAsE No. 20. A.S. This infant was four months old and weighed $7 \mathrm{lb} .8 \mathrm{oz}$. on admission (fig. 6). His birth weight had been $6 \mathrm{lb} .3 \mathrm{oz}$., but there had been 


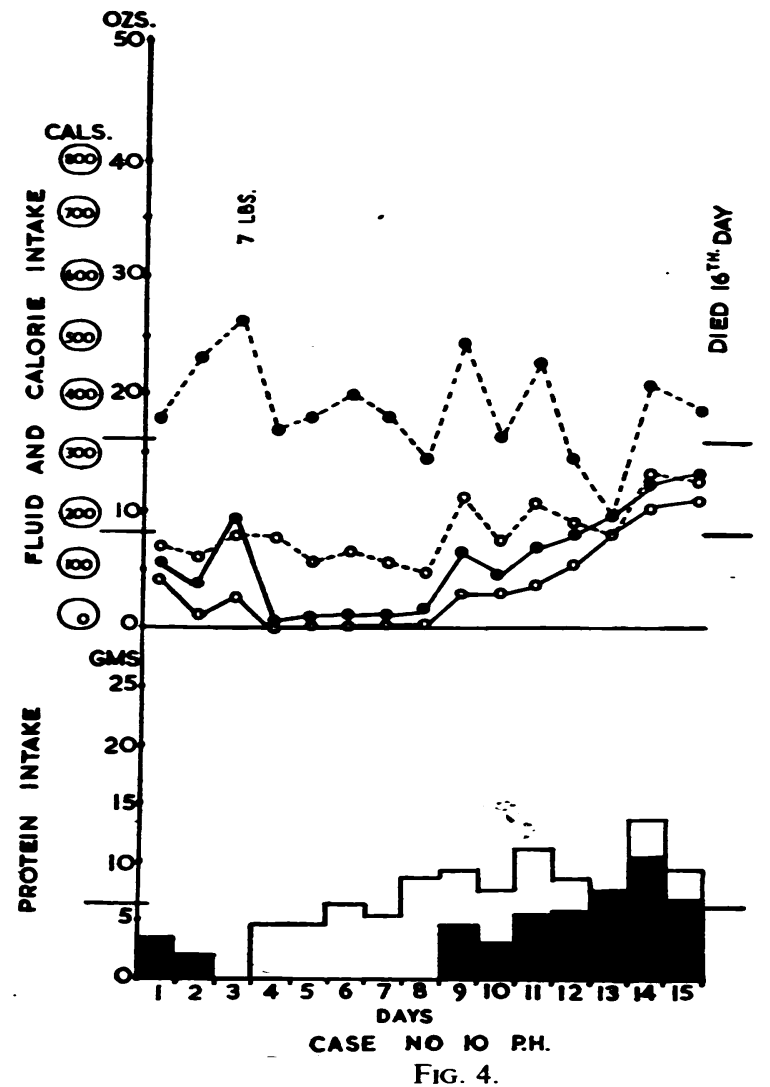

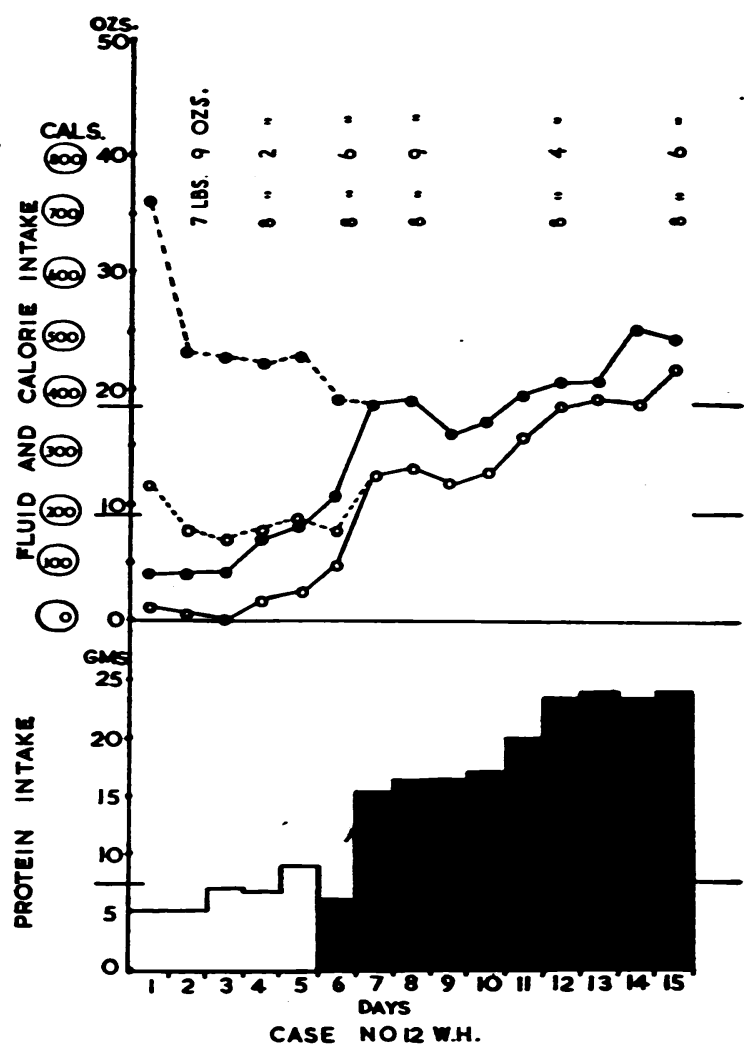

Fig. 5.

relieved by an intravenous infusion during the first day. Maintenance infusions containing 'casydrol " were continued from the second to the seventh day, oral feeding having been introduced on the fourth day when the diarrhoea was well controlled. The infant made uninterrupted progress, but slight oedema was noted from the second to the sixth day. The child, weighing $14 \mathrm{lb}$. $12 \mathrm{oz}$., was discharged well on the twenty-seventh day.

The first three figures illustrate the treatment of peritonitis (1) in a case of prolonged obstruction of the bowel, (2) in one who made an early recovery, and (3) in one with a relapse. There seems to be more tendency for oedema to develop in these cases than in those with gastro-enteritis, in which the extrarenal losses are usually higher. The oedema may be an inevitable complication when an accumulation of gastro-intestinal secretions from the bowel enters the circulation after the relief of an obstruction. This is probably what happened in case 7 (fig. 1) on the fourth day.

The last four charts illustrate the treatment of different types of patient with diarrhoea and vomiting. In case 10 these symptoms were associated with neonatal infection. In case 12 and case 20 they were primary, but case 20 contracted of aural infection were found, but mastoiditis was suspected and mastoidectomy performed.

Antibiotics were prescribed, and dehydration was 


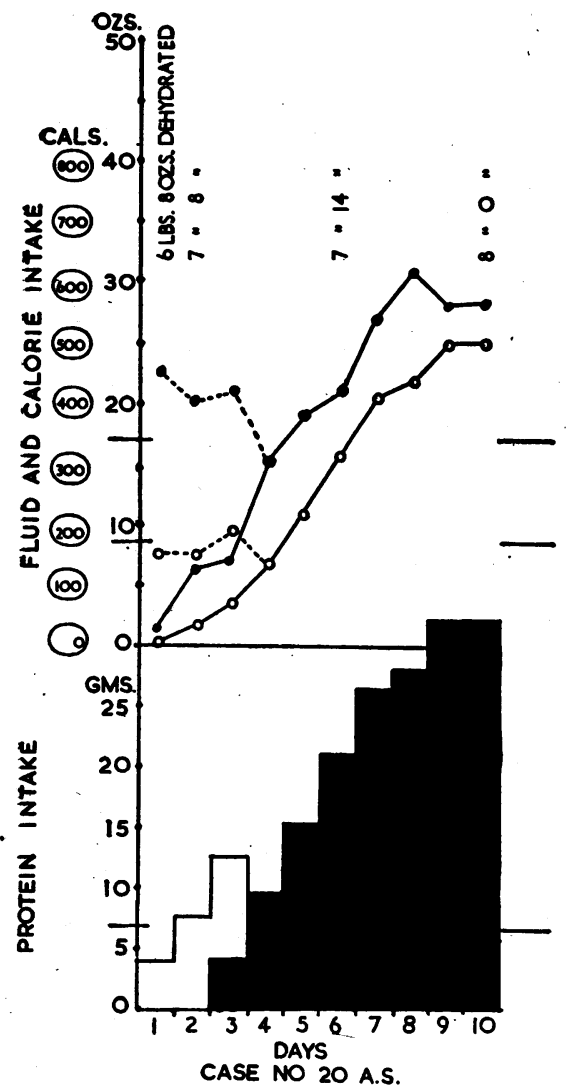

FIG. 6.

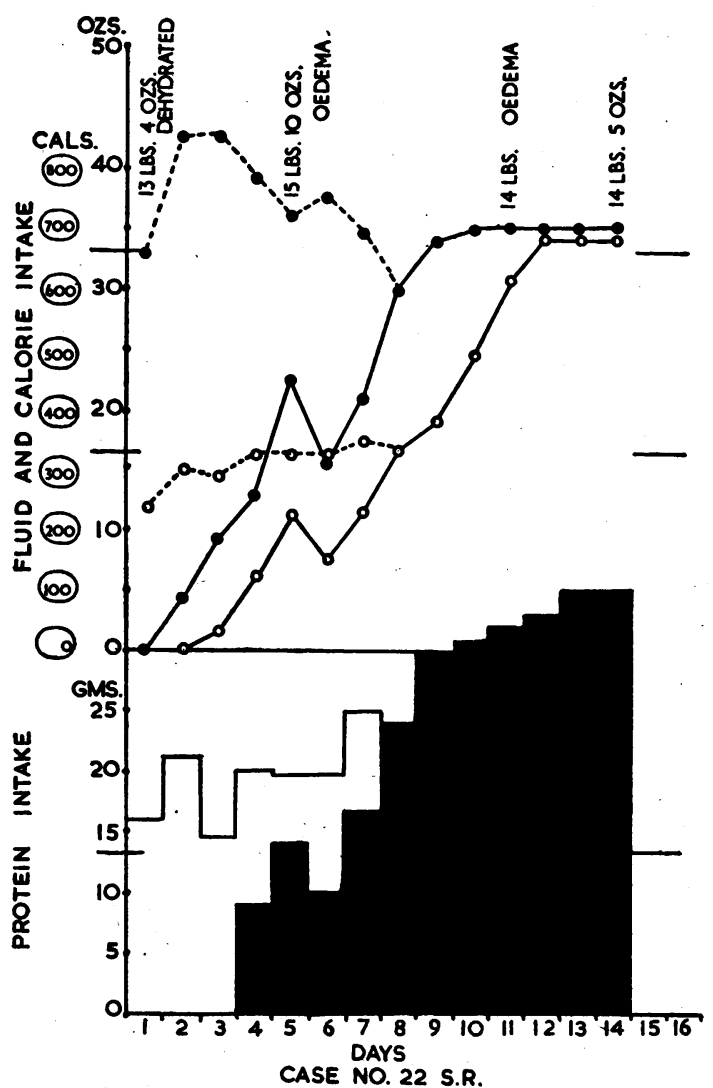

FIG. 7.

his illness when he was already in a severe state of malnutrition. Case 22 began the disease in hospital presumably from cross-infection, although the contact could not be traced.

\section{Discussion}

The advantages of giving protein digests intravenously to adult patients who cannot tolerate oral feeding have been well stressed and summarized by Magee (1948), and the need for protein is relatively greater in infancy than at later ages owing to the demands of growth. Milk protein would seem to be a good source, particularly for young infants whose natural food is milk. In disease, a mixed digest prepared from liver or meat might supply special needs. Plasma should be given only in limited amounts owing to the high content of sodium salts (in citrated preparations it may be even higher than in the circulating plasma (see table 1)), and to the inability of infants to excrete them as efficiently as older subjects (Young, Hallum, and McCance, 1941; Dean and McCance, 1947).

The results of this investigation have shown that the administration of intravenous infusions containing 'casydrol' is practicable and without danger. The benefits following its use have not been clearly

demonstrated, but an impression has been obtained that very sick infants have reached convalescence in a better state of nutrition than those who were treated before these solutions were available, and that some have lived whose chances of survival through a long period of starvation would have been regarded as hopeless. The advantages may be due partly to a better balance of sodium and potassium salts (Darrow, 1946; Govan and Darrow, 1946) in the 'casydrol' infusions (see table 1) as well as to the derivatives of protein which they contain. We have noticed that anorexia (a feature frequently associated with acute abdominal conditions) has not been a symptom in the present series. The advent of penicillin and the systematic administration of vitamin supplements parenterally to patients at times when oral feeding is withheld have coincided with the present trial, and each of these factors is likely to have contributed to the results.

Emphasis has not been placed on changes in the weight of our patients during periods when they were receiving intravenous infusions. Wide fluctuations may occur but these do not bear a close relationship to 'true' body weight, because they are affected by differences in the state of hydration. 
Thus patients always gain weight as dehydration is relieved, and a further gain may be due to an increase in body water with or without visible oedema. Dodd and Rapoport (1946) have claimed that gains in weight may be achieved in infants receiving parenteral fluids alone with the use of glucose, whole blood, plasma, and casein hydrolysate solutions. They have failed to stress, however, that their patients on admission were often dehydrated and that, therefore, considerable weight gains were to be expected as the body fluids were being restored. Nevertheless, these authors usually gave their patients (particularly the smaller ones) a higher daily intake of fluid, calories, and protein than the patients in our investigation were receiving, and their weights might therefore be expected to be well maintained. Dodd and Rapoport found that they were able to neglect close control of the total intake of fluid provided that care was taken to avoid an excess of salt. The preparation of hydrolysed casein ('amigen') which they were using has a lower concentration of salt than 'casydrol ' (about half), and therefore it could be given in larger amounts with greater safety. It might be dangerous to copy their practice if 'casydrol', as it is now prepared, were being used. The American workers also used 10 per cent. glucose solution, instead of the 5 per cent. Solution which is isotonic but provides fewer calories. So far, we have had no experience of using 10 per cent. glucose solution for maintenance infusions, but if it were well tolerated by the veins it would probably be advantageous. Butler and Talbot (1944), agree with Dodd and Rapoport (1946) that it is practicable to give it to infants for continuous intravenous infusions.

In conclusion, the provision of protein digests such as 'casydrol', suitable for intravenous use in infants, has drawn attention to our lack of knowledge concerning protein metabolism in the conditions which have been described, and nitrogen balance experiments in sick and convalescent infants might enable us to assess and fulfil their needs with greater assurance. The development of methods for preparing fat emulsions suitable for intravenous administration would provide a higher caloric intake which would spare the protein for repair. Despite the present drawbacks, infusions of ' casydrol ' have been considered valuable for cases of severe gastroenteritis, acute abdominal conditions, and the difficult congenital abnormalities of the alimentary tract. A long period of oral starvation, on which ultimate recovery may depend, can be planned with safety, thus allowing the primary site an adequate interval of rest.

\section{Sunmary}

Intravenous infusions of an enzymic digest of casein ('casydrol') with glucose have been given to sixty-one infants without any reactions being observed. Necropsy findings suggest that there was an embolic spread of infection in one case as the result of the infusion, while in three others this complication might have been due to the infusion, but was more probably due to a focus of infection already present in the body. An infusion of $2 \frac{1}{2}$ per cent. 'Casydrol' in 5 per cent. glucose solution was well tolerated by the veins. A 'closed ' method of administering intravenous fluids must be used to safeguard patients from the risks of contamination of the infusion.

Twenty-six infants received infusions of 'casydrol' for a period of several days so that the treatment was likely to have affected the course of their disease, and of these nineteen survived, and seven died. Other factors, such as plasma and blood transfusions and parenteral supplements of vitamin preparations, probably contributed to the good results in the patients who recovered.

Further knowledge of the nitrogen metabolism of sick and convalescent infants is needed, so that a full use may be made of the preparations now available for intravenous administration.

The authors wish to thank Professor Sir Leonard G. Parsons and Professor J. M. Smellie for their helpful criticism and advice, and the medical staff of the Children's Hospital, Birmingham, for allowing them to work in their wards. W.F.Y. received a grant from the Medical Research Council, and Y.J.W. a Research Scholarship from the Department of Paediatrics and Institute of Child Health, while E.A.B. and W.F.Y. each held the Caroline Harrold Research Fellowship of Birmingham University during part of the time these investigations were in progress, and these awards are gratefully acknowledged. The Medical Research Council supplied a part and the manufacturers a part of the 'casydrol' solution used in this investigation.

The co-operation of the ward sisters has been invaluable, and Mr. J. G. Williamson, the photographer, has been of great assistance in preparing the diagrams.

The special preparations referred to in this paper were supplied by the following :

'Amigen ' by Mead Johnson \& Co., U.S.A.; 'casydrol' by Genatosan Ltd.; 'beminial' by Warner Bros., U.S.A.; 'synkavit' and 'heparglandol' by Roche Products, Ltd.; 'plexan' by Glaxo Laboratories, Ltd.; and 'davitamon A. forte' by Organon Laboratories, Ltd.

\section{REFERENCES}

Brand, E., Kassell, B., and Saidel, L. J. (1944). J. clin. Invest., 23, 437.

Block, R. J., and Bolling, D. (1944). Amer. J. Pharm., 116, 368.

Butler, A. M., and Talbot, N. B. (1944). New Engl. J. Med., 231, 585, 621.

Dean, R. F. A., and McCance, R. A. (1947). Nature, 160,904 .

Darrow, D. C. (1946). J. Pediat., 28, 515.

Dodd, K., and Rapoport, S. (1946). J. Pediat., 29, 758.

Forbes, G. B., Donnell, G., and Herweg, J. C. (1947). J. Pediat., 31, 375. 
Govan, C. D., and Darrow, D. C. (1946). J. Pediat., 28, 541 .

Jonxis, J. H. P. (1946). Maandschr. Kindergeneesk., 14, 105.

Kozoll, D. D., Hoffiman, W. S., and Meyer, K. A. (1945). Arch. Surg., Chicago, 51, 59.

Magee, H. E. (1948). Brit. med. J., 1, 4.

Rapoport, S., Dodd, K., Clark, M., and Syllm, I. (1947). Amer. J. Dis. Child., 73, 391.
Shohl, A. T. (1943). J. clin. Invest., 22, 257. Butler, A. M., Blackfan, K. D., and McLachlan, E. (1939). J. Pediat., 15, 469.

Walton, J. N. (1947). Lancet, 1, 662.

Williamson, M. B. (1944). J. Biol. Chem., 156, 47.

Young, W. F., Hallum, J. L., and McCance, R. A. (1941). Arch. Dis. Childh., 16, 243. Bishop, E. A., Hickmans, E. M., and Williams, Y. J., (1949). To be published. 